\title{
Imaging Analysis of Ameloblastoma of Mandible - 5 Cases
}

\author{
S. Jayachandran ${ }^{*}$ and Khushboo Singh
}

\author{
Department of Oral Medicine and Radiology, Tamil Nadu, Government Dental College and Hospital, Chennai \\ -600 003, India
}

\begin{abstract}
Ameloblastoma is the most common odontogenic tumor of the jaws. It is seen in all age groups but the lesion is most commonly diagnosed in the third and fourth decades. It is often asymptomatic, presents as a slowly enlarging swelling or an incidental finding on a radiograph. Radiologically, usually appears as multilocular radiolucency with well defined and corticated borders but can also presents as unilocular radiolucency. Other radiological findings commonly associated are tooth displacement, and root resorption. Computed tomography (CT) shows cortical expansion and in some cases even cortical perforation. Ameloblastoma is a locally destructive tumor with a propensity for recurrence if not entirely excised. In this paper, we report 5 cases of ameloblastoma of mandible collected over the period of 8 months with various imaging findings and their analysis using panoramic radiograph under conventional radiography and CT scan under advanced imaging which may further aid in optimal treatment planning and outcome.
\end{abstract}

Keywords: Ameloblastoma, mandible, CT, bicortical expansion.

\section{INTRODUCTION}

Ameloblastoma is a locally destructive, benign neoplasm arising from odontogenic epithelial origin [1]. Regezi and Sciubba reported that ameloblastoma accounts for $11 \%$ of all odontogenic tumors in the jaw [2]. It may arise from the enamel organ, remnants of dental lamina, the lining of an odontogenic (dentigerous) cyst, or possibly from the basal epithelial cells of the oral mucosa [3]. It is a slow-growing, persistent, and locally aggressive neoplasm. Its peak incidence is in the 3rd to 4th decades of life and has an equal sex distribution. Most commonly involves mandible with $70 \%$ of these arising in the molar-ramus area and they are occasionally associated with unerupted third molar teeth [4]. It may be detected during the course of routine radiography. There are three clinicoradiological forms of ameloblastomas, namely solid or multicystic tumors $(86 \%)$, unicystic tumors (13\%), and peripheral tumors (1\%) [5]. Ameloblastoma can be radiologically unilocular or multilocular radiolucency with a honeycomb or soap bubble appearance. Treatment includes wide excision, preferably taking up to $2 \mathrm{~cm}$ of apparently normal bone around the margin. Complete excision is curative but enucleation is followed by recurrence.

\section{CASE 1}

A 50-year-old male patient presented with the chief complaint of swelling on right side of face for past one month. On extraoral examination, a swelling was

*Address corresponding to this author at the Department of Oral Medicine and Radiology, Tamil Nadu Government Dental College and Hospital, Chennai 600 003, India; Tel: +919444185662;

E-mail: drsjayachandranmds@yahoo.com present in right mandibular ramus region, hard in consistency and nontender on palpation. Intraorally, there was no evidence of any swelling. Orthopantamogram(OPG) showed well defined unilocular radiolucent lesion in right mandibular ramus region (Figure 1). Axial section of CT scan revealed a homogenous, hypodense lesion present in right mandibular ramus region extending into angle with bicortical expansion, thinning of cortical plates and perforation of cortical plate lingually (Figure 2). Incisional biopsy was performed and histopathological report gave the diagnosis of follicular ameloblastoma.

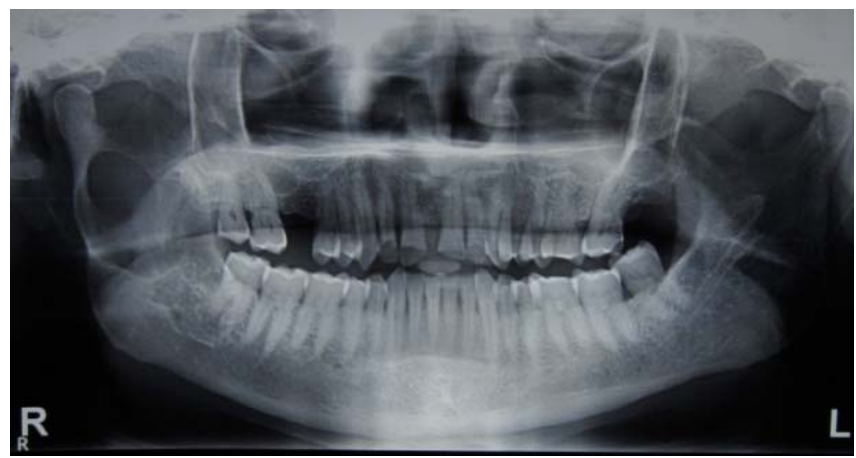

Figure 1: OPG shows a well defined unilocular radiolucent lesion in right mandible ramus.

\section{CASE 2}

A 22-year-old male patient reported with complaints of swelling in lower right teeth region for past two months. Past dental history revealed extraction of 43 due to mobility one year back and also history of root canal treatment in $31,32,41,42,44$, and 45 one month back. There was no evidence of any extraoral swelling. On intraoral examination, a swelling was present in right mandibular alveolus region of 42,43 and 44 , with normal overlying mucosa, nontender on 


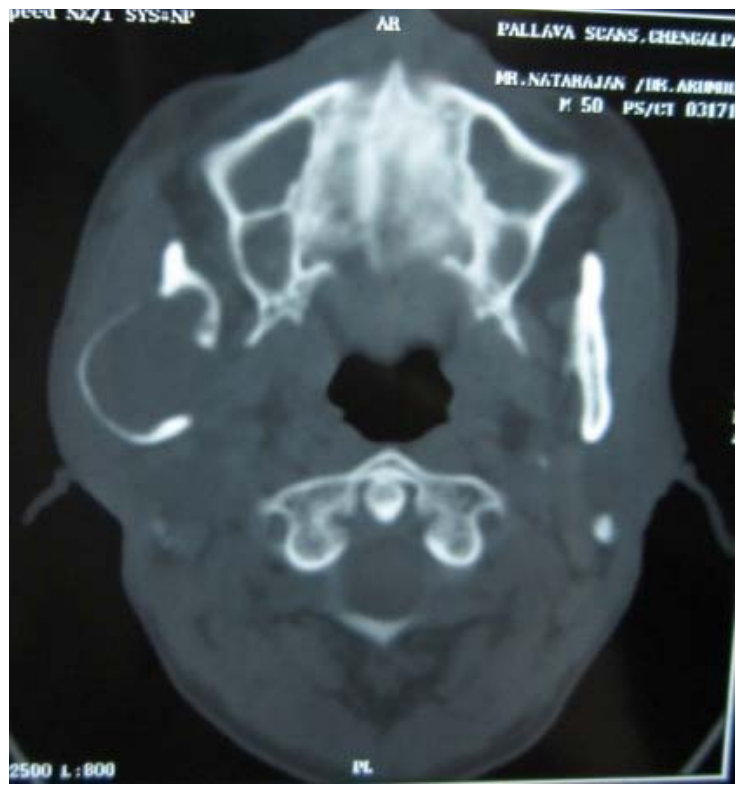

Figure 2: Axial section of CT shows an expansile, hypodense mass in right mandible ramus.

palpation, hard in consistency. OPG showed a welldefined multilocular radiolucency with scalloped borders extending from mesial end of 32 to mesial end of 45 , resorption of apical part of roots of 42,44 , and 45 and displacement of roots of 42 and 44 (Figure 3 ). Axial section of cone beam computed tomography (CBCT) revealed a well defined homogenous, hypodense lesion in right mandibular parasymphysis and body region with expansion, and perforation of buccal cortical plate (Figure 4). Incisional biopsy was performed and histopathological report suggested the diagnosis of follicular ameloblastoma.

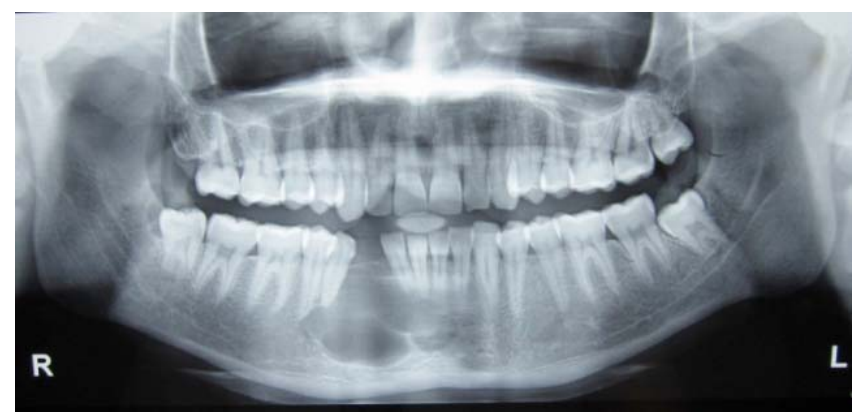

Figure 3: OPG shows a well defined multilocular radiolucent lesion in region of $31,32,41,42,43,44$, and 45 .

\section{CASE 3}

A 27-year-old female patient reported with the complaint of swelling on right side of face for past eight months. Past dental history revealed extraction of 45 and 46 before 8 months. Extraorally, a swelling was present in right mandibular ramus region, hard in consistency and non tender on palpation. OPG showed

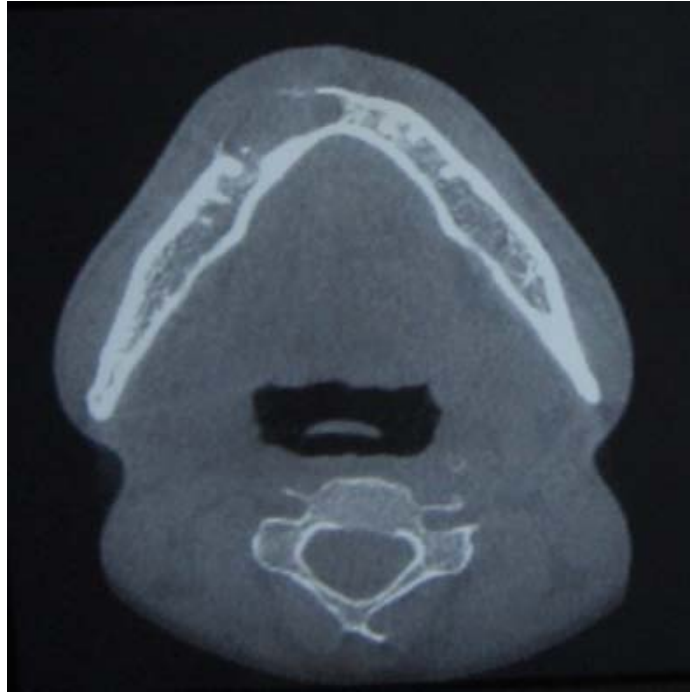

Figure 4: Axial section of CBCT shows an expansile, hypodense mass in right mandibular parasymphysis and body region.

a well-defined multilocular radiolucency with scalloped borders extending from mesial aspect of 47 involving angle, ramus, condyle, and coronoid process with displaced 48 towards anterior border of ramus (Figure 5). Axial CT scan section revealed a homogenous, hypodense lesion in right mandibular ramus region with bicortical expansion and perforation of cortical plate in most of the areas (Figure 6). Incisional biopsy was performed and histopathological report gave the confirmative diagnosis of plexiform ameloblastoma.

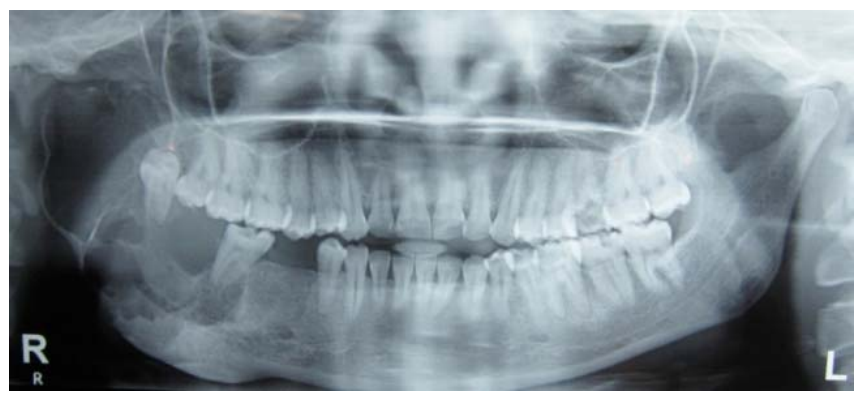

Figure 5: OPG shows multilocular radiolucency involving right mandibular angle, ramus, condyle, and coronoid process.

\section{CASE 4}

A 21-year-old male patient reported with the chief complaint of swelling in lower front teeth region for the past two years. Extraorally, a swelling was present in mandibular anterior region, hard in consistency and non tender on palpation. Intraorally, a swelling was present in alveolus region obliterating vestibule extending from distal surface of 33 to distal surface of 46 , crown of $31,32,41,42,43$ were displaced, overlying mucosa was smooth \& normal, hard in 


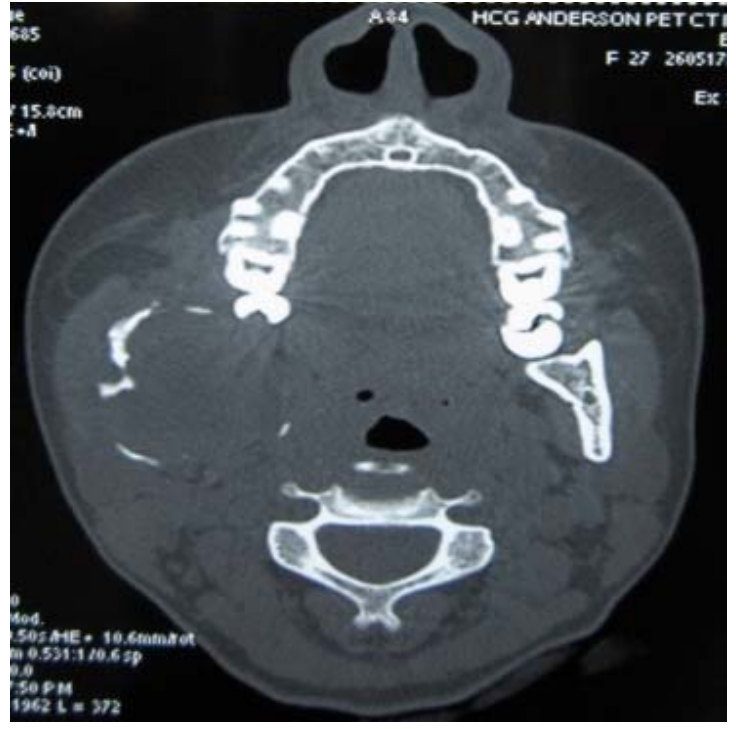

Figure 6: Axial CT scan shows an expansile, hypodense, homogenous lesion in right mandibular ramus.

consistency, non tender on palpation. OPG revealed a well-defined unilocular radiolucency extending from mesial end of 34 to mesial end of 47 with resorption of apical part of roots of $31,32,41,42,43,44,45$, and 46 and displacement of teeth 43,44 , and 45 , also few radiopacities were evident in superior part of lesion may be suggestive of residual bone (Figure 7). Axial CT scan showed a homogenous, hypodense lesion involving mandibular alveolus with bicortical expansion, thinning of cortical plates, and honey comb appearance in anterior region (Figure 8). Incisional biopsy was done. Histopathological report suggested follicullar ameloblastoma.

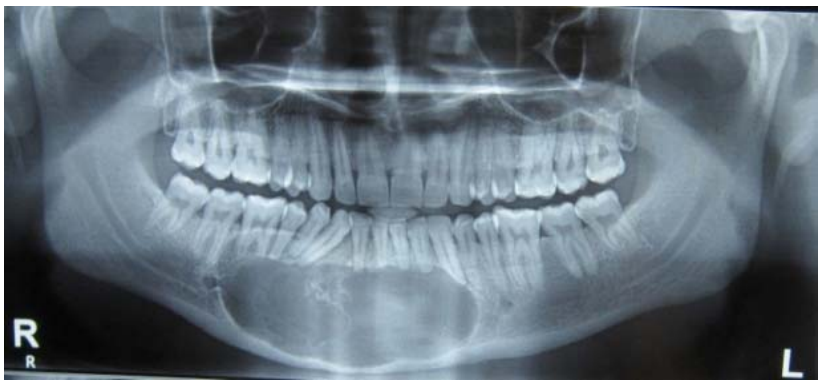

Figure 7: OPG shows a well defined unilocular radiolucency extending from 34 to 47.

\section{CASE 5}

A 20-year-old female patient presented with the chief complaint of swelling in left lower jaw for past three weeks. On extraoral examination, a swelling was evident in left mandibular angle region, hard in consistency, and tender on palpation. Intraorally, there was no evidence of any swelling. OPG showed welldefined unilocular radiolucency lesion extending from

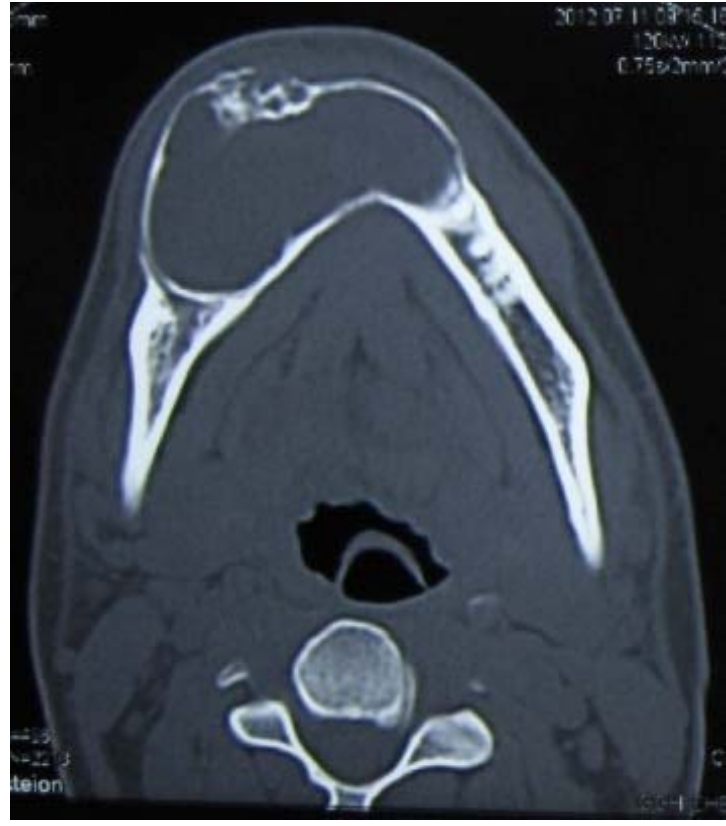

Figure 8: Axial CT scan shows an expansile, hypodense, homogenous lesion in mandible.

mesial root of 37 , involving angle, ramus with absence of 38 and resorption of apical part of distal root of 37 (Figure 9). Axial section of CT scan revealed a homogenous, hypodense lesion present in left mandibular ramus region extending into angle with bicortical expansion, thinning of cortical plates (Figure 10). Incisional biopsy was done. Histopathological report suggested follicullar ameloblastoma.

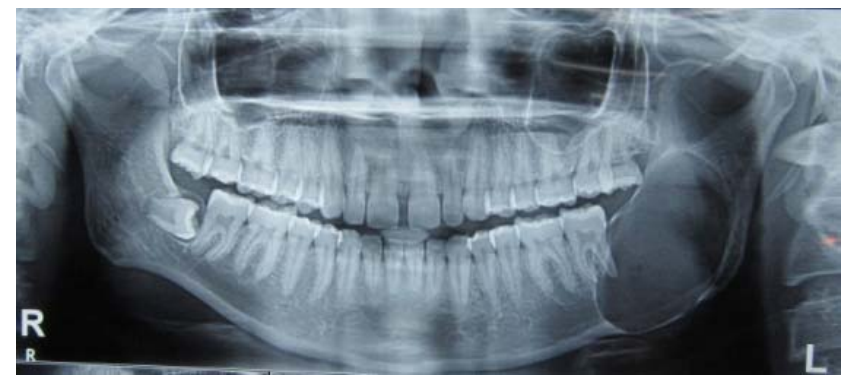

Figure 9: OPG shows well defined radiolucency involving left mandibular angle and ramus.

\section{DISCUSSION}

Ameloblastoma is the most common clinically significant odontogenic tumor of epithelial origin [6]. These tumors shows benign course but are locally invasive. According to literature, this tumor is more common in posterior region of mandible. In this paper, 3 cases involved posterior mandible and 2 cases involved anterior mandible. It often presents as a slow growing, painless swelling. Melvor stated four radiographic features that are significant in ameloblastoma and these include expansion of cortical 


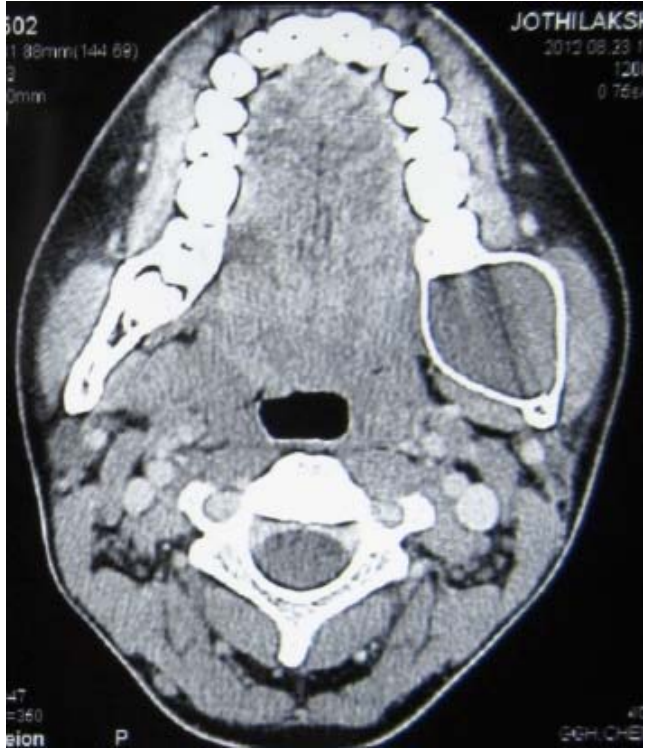

Figure 10: Axial CT scan shows an expansile, hypodense, homogenous lesion in left mandible ramus.

plate, presence of corticated scalloped margins, multilocular appearance of lesion, and the resorption of adjacent roots of teeth [7]. Out of 5 cases, 4 cases showed bicortical expansion, 1 case showed expansion of only buccal cortical plate, 1 case showed perforation of lingual cortex, 1 case showed perforation of buccal cortex, 1 case showed perforation of both buccal and lingual cortex and 2 cases showed no perforation of cortical plates whereas 2 cases showed multilocular appearance with scalloped borders and 3 cases showed unilocular appearance with non scalloped, smooth borders (Table 1). Out of all 5 cases, only 4 lesions were extending in teeth bearing region of which 3 lesions showed root resorption. Usually slow growing lesions cause expansion of cortical plates and resorption of roots whereas aggressive lesion cause destruction of cortical plates but in this paper duration of the lesions do not correlate with cortical expansion and destruction, and resorption of roots. It has been proven that expression of MMP 2 can be found in ameloblastomas and MMP 2 showed correlation with growth and invasion of the lesion [8]. In many cases an unerupted tooth, most often a mandibular third molar, is associated with the tumor [9]. Here 1 case was associated with impacted third molar whereas 1 case was associated with absence of third molar.

Solid/multicystic variant of ameloblastoma is the most common constituting approximately $86 \%$ whereas unicystic variant accounts only $13 \%$. In this paper 3 cases were unicystic variant and 2 cases were multicystic variant. It is of paramount importance to know the particular variety of ameloblastoma as the treatment varies for different types as solid or multicystic variants of ameloblastomas are locally aggressive, and recur if inadequately excised. However, unicystic ameloblastoma was identified as a prognostically distinct entity with less aggressive behavior [10]. The most common histological subtypes of ameloblastoma are follicular, plexiform, acanthomatous, granular and desmoplastic. It was

Table 1: Summary of Imaging Findings of the 5 Cases

\begin{tabular}{|c|c|c|c|c|c|c|c|c|c|}
\hline $\begin{array}{c}\text { Serial } \\
\text { no. }\end{array}$ & Age & Sex & $\begin{array}{c}\text { Site } \\
\text { mandible }\end{array}$ & $\begin{array}{l}\text { Swelling } \\
\text { duration }\end{array}$ & $\begin{array}{c}\text { OPG } \\
\text { appearance }\end{array}$ & $\begin{array}{c}\text { CT } \\
\text { appearance }\end{array}$ & $\begin{array}{l}\text { Cortical } \\
\text { expansion }\end{array}$ & $\begin{array}{c}\text { Radiological } \\
\text { variant }\end{array}$ & $\begin{array}{l}\text { Histo- } \\
\text { pathologic } \\
\text { variant }\end{array}$ \\
\hline 1. & 50 & $M$ & Posterior & 1 month & $\begin{array}{l}\text { Unilocular } \\
\text { radiolucency }\end{array}$ & $\begin{array}{l}\text { Homogenous, } \\
\text { hypodense }\end{array}$ & $\begin{array}{c}\text { Bicortical, } \\
\text { perforation of } \\
\text { lingual cortex }\end{array}$ & Unicystic & Follicular \\
\hline 2. & 22 & M & Anterior & 2 months & $\begin{array}{c}\text { Multilocular } \\
\text { radiolucency, } \\
\text { resorption of } \\
\text { roots of } 42,44 \text {, } \\
45\end{array}$ & $\begin{array}{l}\text { Homogenous, } \\
\text { hypodense }\end{array}$ & $\begin{array}{l}\text { Expansion, } \\
\text { perforation of } \\
\text { buccal cortex }\end{array}$ & Multicystic & Follicular \\
\hline 3. & 27 & $\mathrm{~F}$ & Posterior & 8 months & $\begin{array}{l}\text { Multilocular } \\
\text { radiolucency, } \\
\text { displaced } 48\end{array}$ & $\begin{array}{l}\text { Homogenous, } \\
\text { hypodense }\end{array}$ & $\begin{array}{c}\text { Bicortical } \\
\text { expansion \& } \\
\text { perforation }\end{array}$ & Multicystic & Plexiform \\
\hline 4. & 21 & $M$ & Anterior & 2 years & $\begin{array}{c}\text { Unilocular } \\
\text { radiolucency, } \\
\text { resorption of } \\
31,32,41,42 \\
43,44,45,46\end{array}$ & $\begin{array}{l}\text { Homogenous, } \\
\text { hypodense }\end{array}$ & $\begin{array}{l}\text { Bicortical } \\
\text { expansion }\end{array}$ & Unicystic & Follicular \\
\hline 5. & 20 & $F$ & Posterior & 3 weeks & $\begin{array}{l}\text { Unilocular } \\
\text { radiolucency, } \\
\text { resorption of } \\
\text { 37, missing } 38\end{array}$ & $\begin{array}{l}\text { Homogenous, } \\
\text { hypodense }\end{array}$ & $\begin{array}{l}\text { Bicortical } \\
\text { expansion }\end{array}$ & Unicystic & Follicular \\
\hline
\end{tabular}


shown that the follicular, granular cell and acanthomatous types have a relatively high likelihood of recurrence. In contrast, the desmoplastic and plexiform types show a relatively low potential for recurrence [11]. Treatment includes both conservative and radical modalities which varies according to the variant and behavior of the tumor. Extensive lesions are treated by wide resection while well-defined, small lesions, and in young age patients can be managed by conservative modalities like enucleation and curettage. Most common cause of recurrence is inadequate surgical procedure. Recurrence rate may be as high as $15 \%$ to $25 \%$ after radical treatment and $75 \%$ to $90 \%$ after conservative treatment [12]. Imaging plays vital roles in diagnosis, treatment selection, as well as assessment of disease prognosis and progression. Plain radiographs show distinction only between tumor and normal bone whereas extension into soft tissue cannot be determined. CT scan is necessary because it gives accurate extension of the lesion into the soft tissue, contour of lesion, cortical perforation, extension of lesion into soft tissues making it preferable for diagnosis hence helps in planning appropriate treatment.

In conclusion, ameloblastoma is considered to be a benign, but locally invasive odontogenic tumor. CT scan is preferred imaging modality for appropriate diagnosis and optimal treatment planning. Imaging characteristics of ameloblastoma includes cortical thinning, expansion, and resorption of roots. Perforation of cortical plates is not uncommon in the ameloblastomas. Although after analyzing 5 cases described in this paper, it was concluded that these characteristics does not correlate with the duration of the lesion. This variation may be because of different biological behavior of the lesion in different cases.

\section{CONFLICTING INTEREST}

Nil.

\section{REFERENCES}

[1] Rastogi $R$, Jain $H$. Case report: Desmoplastic ameloblastoma. Indian J Radiol Imaging 2008; 18: 53-55. http://dx.doi.org/10.4103/0971-3026.35819

[2] Williams TP. Management of ameloblastoma: a changing perspective. J Oral Maxillofac Surg 1993; 51: 1064-70. http://dx.doi.org/10.1016/S0278-2391(10)80440-9

[3] Ghandhi D, Ayoub AF, Anthony M, MacDonald G, Brocklebank LM, Moos KF. Ameloblastoma: a surgeon's dilemma. J Oral Maxillofac Surg 2006; 64: 1010-4. http://dx.doi.org/10.1016/j.joms.2006.03.022

[4] Ogunsalu C, Daisley $\mathrm{H}$, Henry $\mathrm{K}$, et al. A new radiological classification for ameloblastoma based on analysis of 19 cases. West Indian Med J 2006; 55: 434-9. http://dx.doi.org/10.1590/S0043-31442006000600013

[5] Philipsen HP, Reichart PA. Classification of odontogenic tumors and allied lesions. Odontogenic tumors and allied lesions Quintessence Pub. Co. Ltd 2004; pp. 21-3.

[6] Torres-Lagares D, Infante-Cossío $P$, Hernández-Guisado JM, Gutiérrez- Pérez JL. Mandibular ameloblastoma. A review of the literature and presentation of six cases. Med Oral Patol Oral Cir Bucal 2005; 10: 231-8.

[7] Melvor J. The radiological features of ameloblastoma. Clin Radiol 1974; 25: 237-42. http://dx.doi.org/10.1016/S0009-9260(74)80060-7

[8] Zhang Y, Guo W, Wang L, Chen X. Molecular markers of tumor invasiveness in ameloblastoma: an update. Ann Maxillofac Surg 2011; 1: 145-49. http://dx.doi.org/10.4103/2231-0746.92780

[9] Hollows P, Fasanmade A, Hayter JP. Ameloblastoma - a diagnostic problem. Br Dent J 2000; 188(5): 243-4.

[10] Robinson L, Martinez MG. Unicystic ameloblastoma: a prognostically distinct entity. Cancer 1977; 40: 2278-85. http://dx.doi.org/10.1002/1097-0142(197711)40:5<2278::AIDCNCR2820400539>3.0.CO;2-L

[11] Vohra FA, Hussain M, Mudassir MS. Ameloblastomas and Their Management: A Review. J Surg Pak 2009; 14(3): 13642

[12] Nakamura N, Higuchi $Y$, Mitsuyasu T, Sandra F, Ohishi M. Comparison of long-term results between different approaches to ameloblastoma. Oral Surg Oral Med Oral Pathol Oral Radiol Endod 2002; 93(1): 13-20. http://dx.doi.org/10.1067/moe.2002.119517

\section{SOURCES OF SUPPORT}

Nil. 